\title{
Diagnosis of type 3 macular neovascularization
}

\author{
Justyna Mędrzycka, Anna Piotrowicz, Joanna Gołębiewska, \\ Radosław Różycki
}

Ophthalmology Teaching Hospital, Military Institute of Aviation Medicine, Warsaw Head of the Teaching Hospital: Radosław Różycki, MD

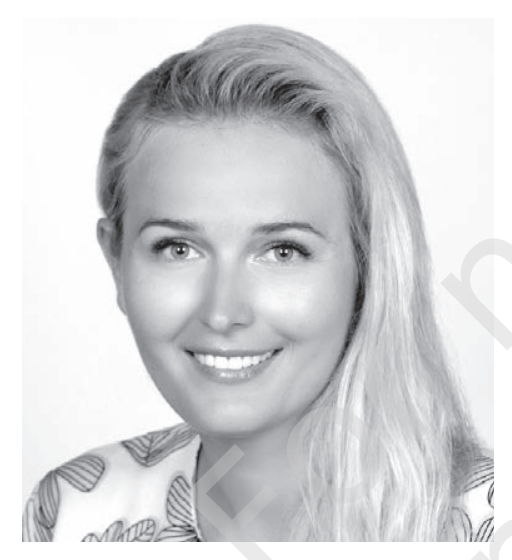

\section{ABSTRACT}

Type 3 macular neovascularization is characterized by a complex of pathological vessels located in the sensory retina. Fundus oculi examination reveals intraretinal hemorrhages, macular edema, hard exudates and pigment epithelial detachments. Indocyanine and fluorescein angiography, OCT and angio-OCT are used for diagnosis and treatment monitoring. The treatment efficacy depends on the disease severity and the therapy applied.

Key words: wet age-related macular degeneration, macular neovascularization, optical coherence tomography angiography, anti-VEGF therapy 


\section{INTRODUCTION}

Type 3 macular neovascularization (MNV), formerly named as retinal angiomatous proliferation (RAP), is one of the forms of wet age-related macular degeneration (wAMD) - a chronic and progressive disease that is the leading cause of central visual field loss in patients over the age of 50. year of life [1].

The first reports on anastomoses between the retinal and choroidal circulations were described over 100 years ago by Oller. In 1992, Hartnett et al. described retinal vascular abnormalities as a term for retinal neovascularization [2]. Not until 2001 Yannuzzi et al. introduced the term of retinal vascular proliferation to refer to vascular abnormalities that develop in the inner part of the retina and spread towards the retinal pigment epithelium (RPE).

\section{CHARACTERISTICS OF TYPE 3 MACULAR NEOVASCULARIZATION}

The prevalence of MNV3 is estimated to be approximately 15-20\% of newly diagnosed wAMD cases among Caucasians. However, these statistics may be slightly underestimated due to the previous lack of special imaging methods. Unlike the other types of wAMD, which occur equally in men and women, MNV3 is more frequently found in females. The disease is usually bilateral, although its course may be asymmetric $[1,3,4]$. Campa et al. demonstrated that in $1 / 3$ of patients diagnosed with unilateral MNV3 lesions in the other eye developed within 3 years [5]. MNV3 is characterised by a poor prognosis with typical rapid progression through all stages of the disease, including scar formation and retinal atrophy [3]. There are also reports on the influence of genetic factors involved in the development of this type of neovascularization, such as the ARMS2/ HTRA gene polymorphism [6].

\section{DIAGNOSTIC METHODS OF TYPE 3 MACULAR NEOVASCULARIZATION}

Indocyanine green angiography (ICGA), which allows imaging of hyperfluorescent foci, the so-called hot spots, has been the gold standard in the diagnosis of MNV3 for years $[7,8]$. Due to more difficult availability of ICGA, fluorescein angiography (FA) is more frequently used in practice (fig. 1). Currently, non-invasive imaging methods, such as optical coherencetomography(OCT)andopticalcoherencetomography angiography (angio-OCT), are most commonly used in the diagnosis of MNV3 (fig. 2).

On OCT, intraretinal hyperreflective foci may be the first sign of MNV3, followed by the appearance of intraretinal fluid spaces and retinal-choroidal anastomoses (fig. 3) During the course of the disease, there is PRE detachment and increased amounts of intra- and subretinal fluid (fig. 4) [9, 10]. The introduction to ophthalmologic diagnostics of angio-OCT examination allowed imaging of retinal diseases in different vascular layers, which confirmed that pathological vessels in MNV3 have their origin in the deep plexus of the retina.

\section{FIGURE}

Type 3 macular neovascularization. FA shows PED and a focus of hyperfluorescence that intensifies during the examination with widening of its borders. OCT-B scan confirms the presence of pigment epithelial detachment with intraretinal fluid and hyperreflective foci.

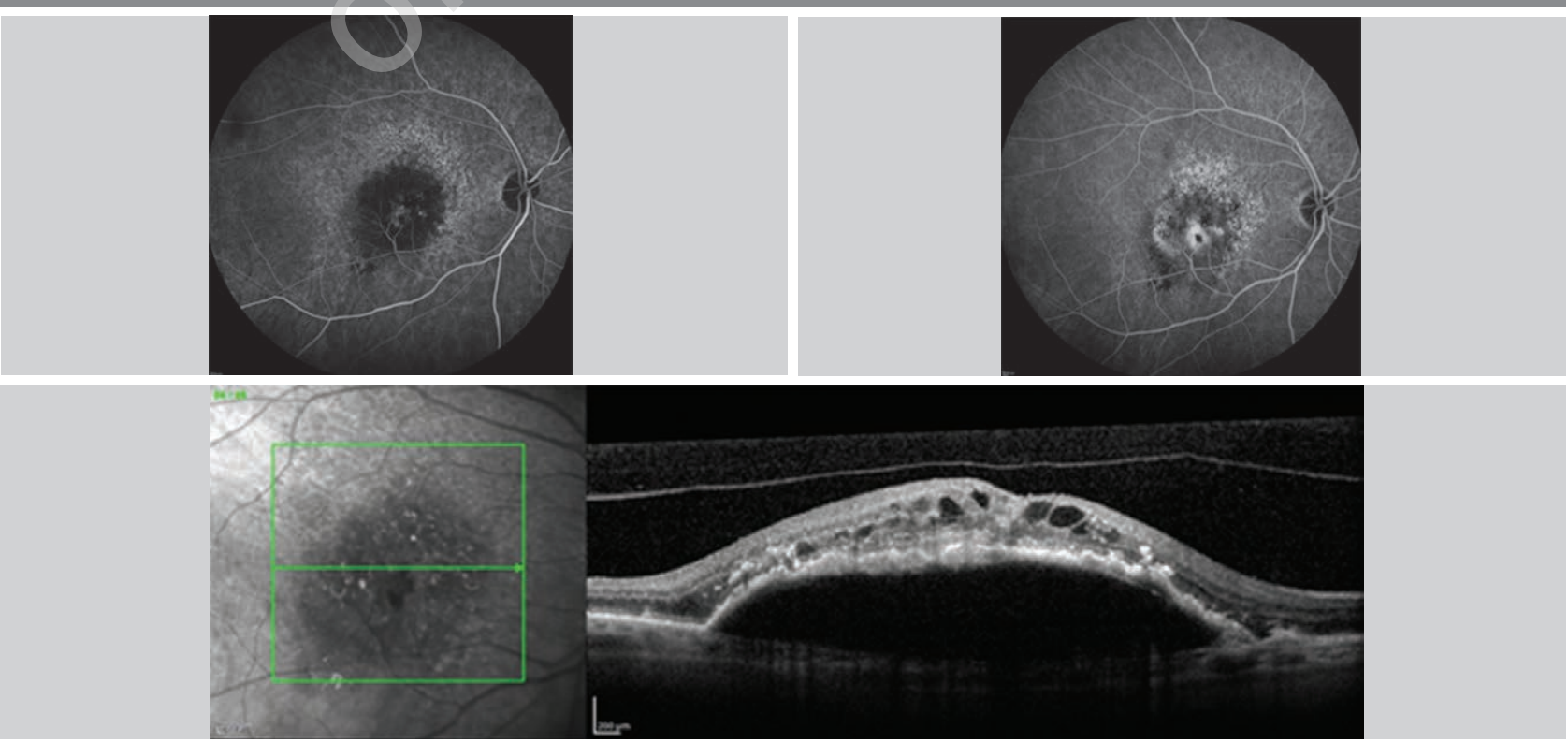




\section{FIGURE ( 2}

In angio-OCT, at the level of the outer retina, there is flow in pathological vessels proliferating as a glomerular lesion marked with arrows.

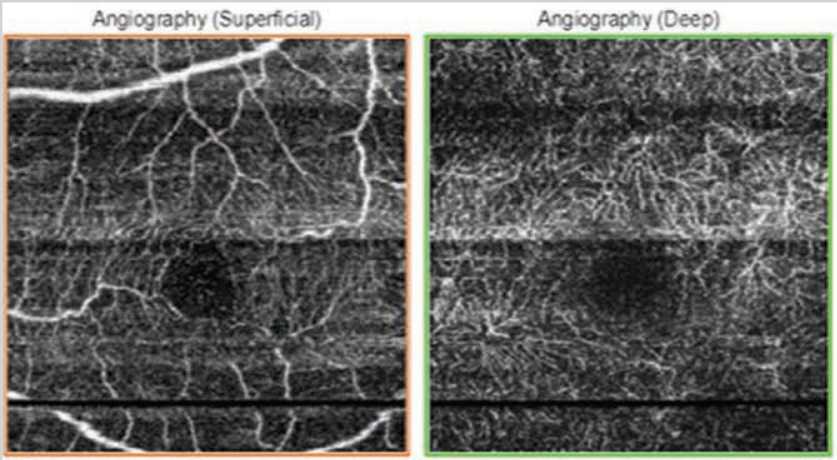

$1 \mathrm{LLM}+26 \mathrm{fm} \sim \mathrm{IPL} / \mathrm{NL}+15.6 \mathrm{fm}$

IPLINL $+156 \mathrm{ym} \sim$ IPLINL + $702 \mathrm{vm}$
OCT B-Scan

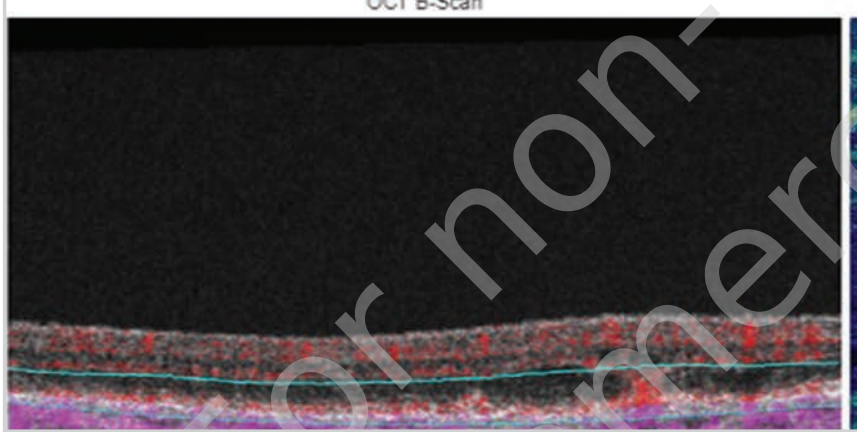

Angiography (Quter retina)

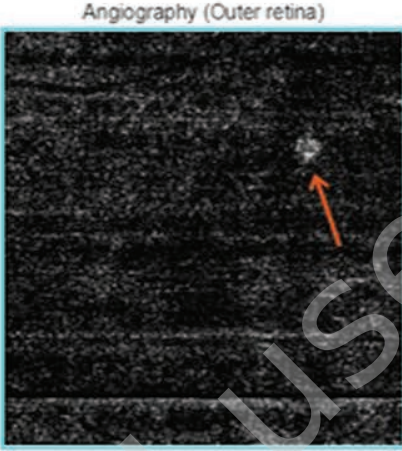

IPLANL $+70.2 \mathrm{um} \sim \mathrm{BM}+0.0 \mathrm{um}$ Density Map

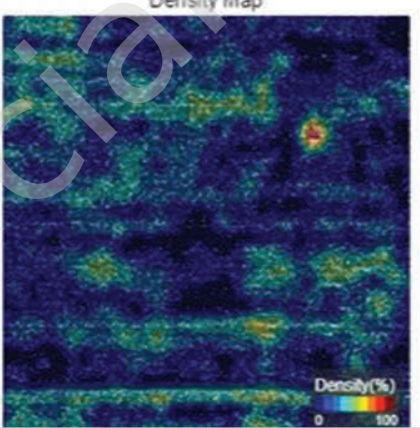

Angiography (Choriocapilanis)

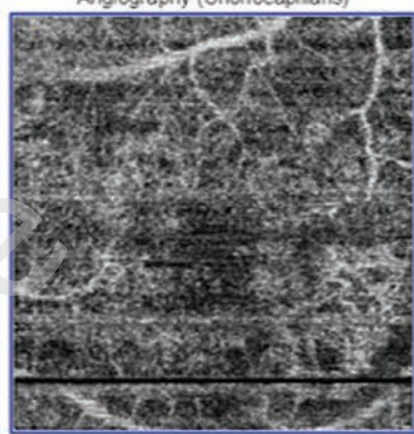

$\mathrm{BM}+0.0 \mathrm{ym} \sim \mathrm{BM}+10.4 \mathrm{um}$ Fundus

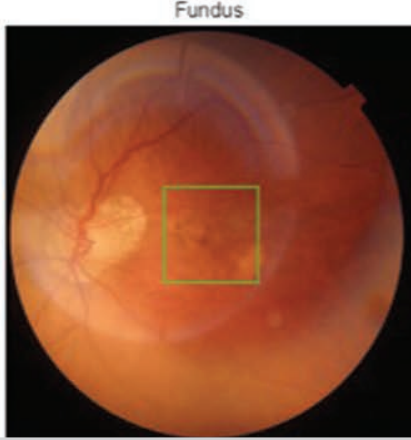

\section{FIGURE $(3$}

RAP progression. A. Single cysts of intraretinal fluid are seen. B. Progression of retinal edema. C. Cystoid macular edema and retinal-choroidal anastomoses.
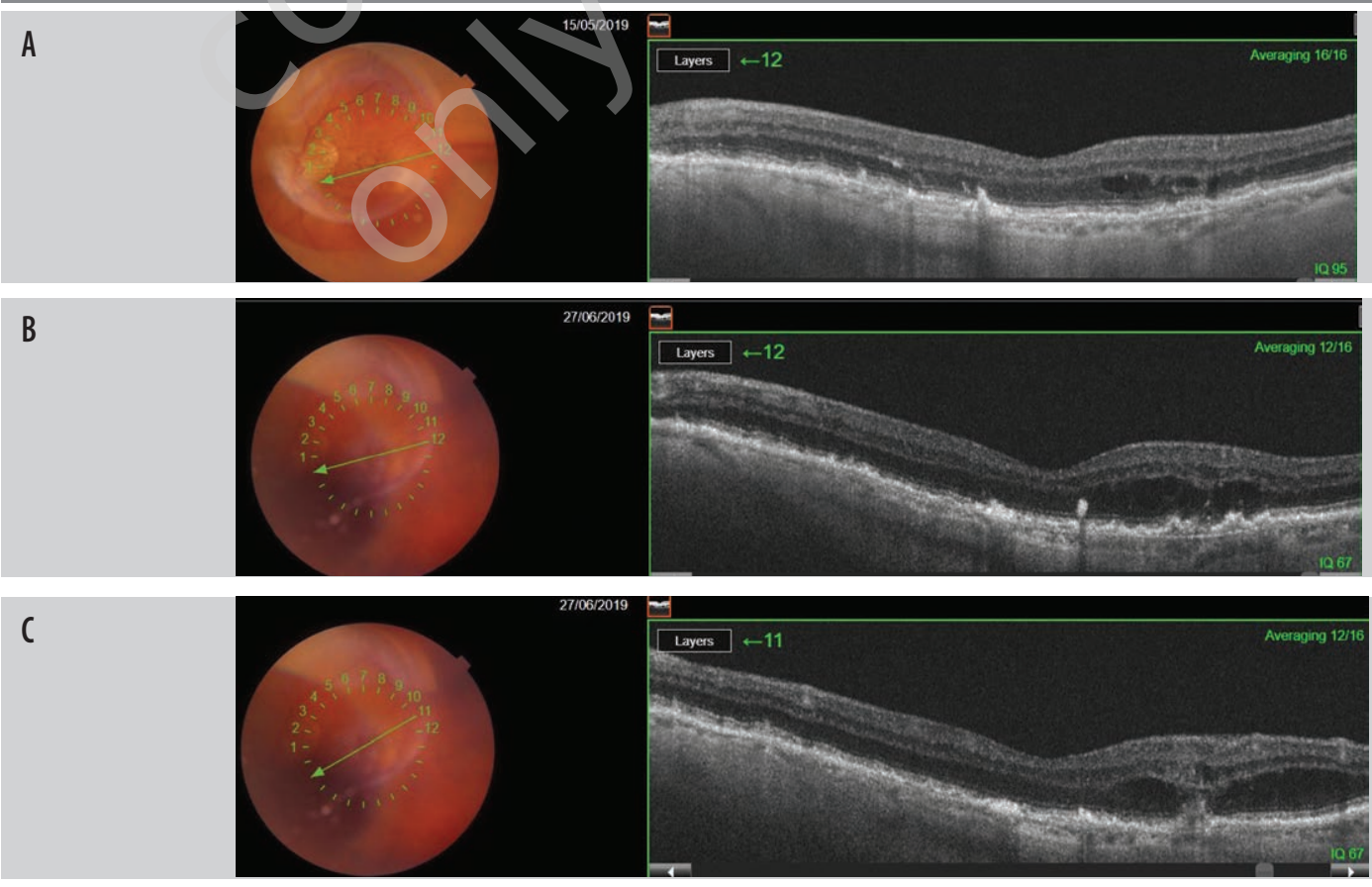

O P H T H A T H E R A P Y Copyright @ Medical Education

Vol. $8 / \operatorname{Nr} 3(31) / 2021($ s. 153-158) https://www.journalsmededu.pl/index.php/ophthatherapy/index: 26.04.2023; 10:11,53 


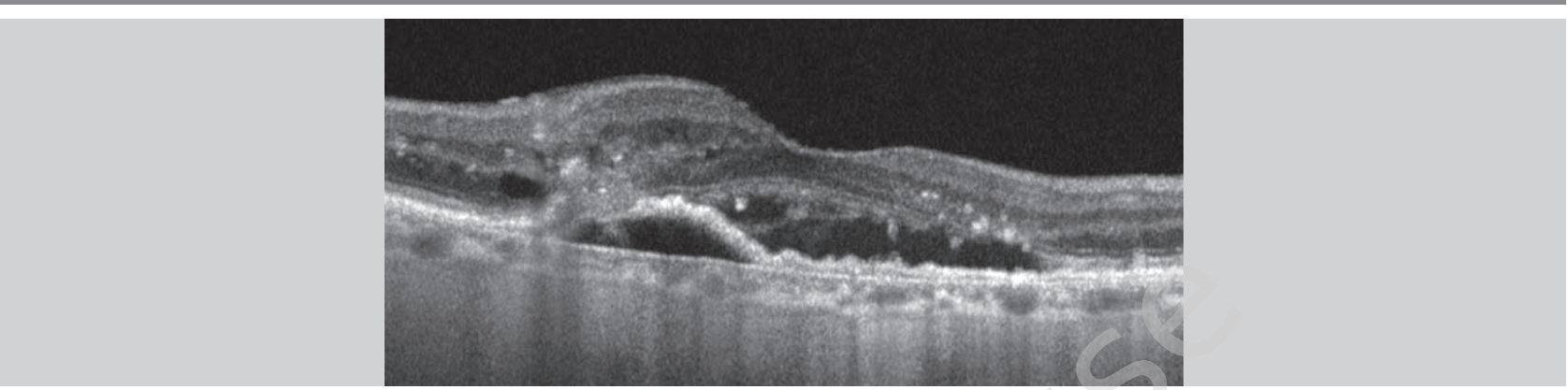

Yannuzzi et al. proposed three stages to evaluate the evolution of MNV3 based on clinical symptoms and lesions in the choroid (tab. 1):

- grade 1. - intraretinal neovascularization (IRN)

The neovascularization is located deep in the inner layers of the retina and targets the anterior and posterior retinal borders. Physical examination often reveals intraretinal hemorrhages and retinal edema. OCT examination not infrequently reveals small intraretinal hyperreflective foci, often accompanied by subretinal fluid (SRF). Focal pigment leakage may be demonstrated on indocyanine angiography.

- grade 2. - subretinal neovascularization (SRN)

Intraretinal neovascularization extends deeper towards the RPE, beyond the photoreceptor layer with involvement of the subretinal space.

Sensory retinal detachment, hemorrhages and increasing intraretinal edema are often observed. When neovascularization joins the RPE, serous retinal detachment may occur. OCT examination reveals increasing intraretinal edema and serous detachment of pigment epithelium in addition to the lesions of the previous stage.

- grade 3. - choroidal neovascularization (CNV)

The process of neovascularization further spreads downward, contributing to retinal-choroidal anastomosis (RCA), often with associated pigment epithelium detachment (PED) and hard exudates. Fluorescein and indocyanine angiography reveals connections between the vessels of the retina and the choroid $[1,3]$.

\section{CONCLUSION}

Early and correct evaluation of the disease stage is essential for choosing a treatment method. Despite numerous studies, no single, consistent protocol for the treatment of retinal proliferative angiomatosis has been developed to date. Previous attempts have been made to treat MNV3 with photodynamic therapy (PDT) using verteporfin, however, studies have shown that the results were unsatisfactory in monotherapy $[11,12]$. The next step in treatment was to combine PDT with triamcinolone injection into the vitreous body. The effects seemed to be quite promising, demonstrating stabilization of visual acuity and reduction of PED, however, this method is limited due to frequent complications in the form of cataracts and increase in intraocular pressure (IOP) $[13-15,18]$. Anti-vascular endothelial growth factor therapy (anti-VEGF) in intravitreal injections is currently the most commonly used treatment method.

\section{TABLE}

\section{Features of evolution of MNV3 lesions on OCT and angio-OCT.}

\begin{tabular}{|c|c|c|c|}
\hline MNV3 stages & $\begin{array}{l}\text { Lesions on ophthalmoscopic } \\
\text { examination }\end{array}$ & Lesions on OCT & $\begin{array}{l}\text { Lesions } \\
\text { on angio-OCT }\end{array}$ \\
\hline $\begin{array}{l}\text { Intraretinal } \\
\text { neovascularization }\end{array}$ & $\begin{array}{l}\text { - intraretinal hemorrhages, } \\
\text { retinal edema, druses }\end{array}$ & $\begin{array}{l}\text { - intraretinal hyperreflective foci, } \\
\text { subretinal fluid }\end{array}$ & $\begin{array}{l}\text { neovascularization in the inner reti- } \\
\text { nal layers }\end{array}$ \\
\hline $\begin{array}{l}\text { Subretinal } \\
\text { neovascularization }\end{array}$ & $\begin{array}{l}\text { - intraretinal hemorrhages, } \\
\text { increasing retinal edema, } \\
\text { serous neurosensory reti- } \\
\text { nal detachment may occur }\end{array}$ & $\begin{array}{l}\text { - cystoid macular edema, serous } \\
\text { detachment of pigment epithe- } \\
\text { lium with subretinal fluid }\end{array}$ & $\begin{array}{l}\text { serous PED, neovascularization closer } \\
\text { to the RPE that extends beyond the } \\
\text { photoreceptor layer }\end{array}$ \\
\hline $\begin{array}{l}\text { Choroidal } \\
\text { neovascularization }\end{array}$ & - hard exudates & $\begin{array}{l}\text { - extensive fibrovascular PED, } \\
\text { intra- and subretinal fluid }\end{array}$ & - $\quad$ retinal and vascular anastomoses \\
\hline
\end{tabular}

PED - pigment epithelium detachment; RPE - retinal pigment epithelium. 
Clinical studies mostly confirm effective maintenance or improvement of visual acuity and reduction of exudate in affected eyes [16, 17], however there are also reports on local deterioration, including retinal pigment epithelium atrophy [19].

Numerous attempts have been made to treat MNV3 to date, however, therapeutic management has not been standardized. Monotherapy with anti-VEGF offers good short-term results but requires frequent, systematic reapplications. Triamcinolone treatment with PDT appears to have rapid therapeutic effects, but with numerous side effects. There is still too little data to solve which therapeutic modality has the greatest treatment benefit.

Figures: from the author's own materials.

\section{CORRESPONDENCE Justyna Mędrzycka, MD \\ Ophthalmology Teaching Hospital, Military Institute of Aviation Medicine, Warsaw 01-755 Warszawa, ul. Krasińskiego 54/56 e-mail: gryszkiewicz84@wp.pl}

\begin{abstract}
ORCID
Justyna Mędrzycka - ID - http://orcid.org/0000-0001-9578-719X Anna Piotrowicz - ID - http://orcid.org/0000-0003-3910-6251 Joanna Gołębiewska - ID - http://orcid.org/0000-0002-3013-4363 Radosław Różycki - ID - http://orcid.org/0000-0001-7040-026X
\end{abstract}

\section{References}

1. Yannuzzi LA, Freund KB, Takahashi BS. Review of retinal angiomatous proliferation or type 3 neovascularization. Retina. 2008; 28(3): 375-84.

2. Hartnett ME, Weiter JJ, Garsd A et al. Classification of retinal pigment epithelial detachments associated with drusen. Graefes Arch Clin Exp Ophthalmol. 1992; 230(1): 11-9. http://doi.org/10.1007/BF00166756.

3. Tsai ASH, Cheung N, Gan ATL et al. Retinal angiomatous proliferation. Surv Ophthalmol. 2017; 62(4): 462-92. http://doi.org/10.1016/ j.survophthal.2017.01.

4. Gołębiewska J, Hautz W. Zastosowanie angio-OCT w diagnostyce i terapii okulistycznej - część l. OphthaTherapy. 2016; 3(3): 161-71.

5. Campa C, Harding S, Pearce I et al. Incidence of neovascularization in the fellow eye of patients with unilateral retinal angiomatous proliferation. Eye. 2010; 24: 1585-9. http://doi.org/10.1038/eye.2010.88.

6. Kałużny JJ, Zabel K, Zabel P. Proliferacje naczyniakowate siatkówki - epidemiologia, obraz kliniczny i leczenie. Okulistyka. 2021: 21-6.

7. Bearelly S, Espinosa-Heidmann DG, Cousins SW. The role of dynamic indocyanine green angiography in the diagnosis and treatment of retinal angiomatous proliferation. Br J Ophthalmol. 2008; 92(2): 191-6.

8. Öztaş Z, Menteş J. Retinal Angiomatous Proliferation: Multimodal Imaging Characteristics and Follow-up with Eye-Tracked Spectral Domain Optical Coherence Tomography of Precursor Lesions. Turk J Ophthalmol. 2018; 48(2): 66-9.

9. Rispoli M, Cennamo G, Di Antonio L et al. Imaging Biomarkers in Exudative AMD. Biomedicines. 2021; 9(6): 668.

10. Querques G, Miere A, Souied EH. Optical Coherence Tomography Angiography Features of Type 3 Neovascularization in Age-Related Macular Degeneration. Dev Ophthalmol. 2016; 56: 57-61. http://doi.org/10.1159/000442779. Epub 2016.

11. Boscia F, Parodi MB, Furino C et al. Photodynamic therapy with verteporfin for retinal angiomatous proliferation. Graefes Arch Clin Exp Ophthalmol. 2006; 244(10): 1224-32. http://doi.org/10.1007/s00417-005-0205-2. Epub 2006.

12. Stoffelns BM, Kramann C, Schoepfer K. Laserfotokoagulation und photodynamische Therapie (PDT) zur Behandlung der retinalen angiomatösen Proliferation (RAP) bei feuchter altersabhängiger Makuladegeneration (AMD) [Laser photocoagulation and photodynamic therapy (PDT) with verteporfin for retinal angiomatous proliferation (RAP) in age-related macular degeneration (AMD)]. Klin Monbl Augenheilkd. 2008; 225(5): 392-6. http://doi.org/10.1055/s-2008-1027251.

13. Rouvas AA, Papakostas TD, Vavvas D et al. Intravitreal ranibizumab, intravitreal ranibizumab with PDT, and intravitreal triamcinolone with PDT for the treatment of retinal angiomatous proliferation: a prospective study. Retina. 2009; 29(4): 536-44. http://doi.org/10.1097/ IAE.0b013e318196b1de.

14. Krebs I, Krepler K, Stolba U et al. Retinal angiomatous proliferation: combined therapy of intravitreal triamcinolone acetonide and PDT versus PDT alone. Graefes Arch Clin Exp Ophthalmol. 2008; 246(2): 237-43. http://doi.org/10.1007/s00417-007-0651-0. Epub 2007.

15. Nakano S, Honda S, Oh H et al. Effect of photodynamic therapy (PDT), posterior subtenon injection of triamcinolone acetonide with PDT, and intravitreal injection of ranibizumab with PDT for retinal angiomatous proliferation. Clin Ophthalmol. 2012; 6: 277-82. http:// doi.org/10.2147/OPTH.S29718. Epub 2012. 
16. Saito $M$, lida $T$, Kano M. Combined intravitreal ranibizumab and photodynamic therapy for retinal angiomatous proliferation. Am J Ophthalmol. 2012; 153(3): 504-14.e1. http://doi.org/10.1016/j.ajo.2011.08.038. Epub 2011.

17. Malamos $\mathrm{P}$, Tservakis I, Kanakis $\mathrm{M}$ et al. Long-Term Results of Combination Treatment with Single-Dose Ranibizumab plus Photodynamic Therapy for Retinal Angiomatous Proliferation. Ophthalmologica. 2018; 240(4): 213-21. http://doi.org/10.1159/000487610. Epub 2018.

18. Mantel I, Ambresin A, Zografos L. Retinal angiomatous proliferation treated with a combination of intravitreal triamcinolone acetonide and photodynamic therapy with verteporfin. Eur J Ophthalmol. 2006; 16(5): 705-10. http://doi.org/10.1177/112067210601600507.

19. Hata M, Yamashiro K, Oishi A et al. Retinal pigment epithelial atrophy after anti-vascular endothelial growth factor injections for retinal angiomatous proliferation. Retina. 2017; 37(11): 2069-77. http://doi.org/10.1097/IAE.0000000000001457.

Authors' contributions:

Justyna Mędrzycka: 40\%; Anna Piotrowicz: 25\%; Joanna Gołębiewska: 25\%;

Radosław Różycki: 10\%.

Conflict of interest:

None.

Financial support:

None.

Ethics:

The content presented in the article complies with the principles of the Helsinki Declaration, EU directives and harmonized requirements for biomedical journals. 